\title{
Translaryngeal open ventilation to treat acute respiratory failure in acute exacerbation of chronic obstructive pulmonary disease. A preliminary report
}

\author{
[La ventilation ouverte, translaryngée, pour traiter l'insuffisance respiratoire aiguë
}

d'une maladie pulmonaire obstructive chronique : un compte rendu préliminaire]

Yoanna Skrobik MD FRCPC, ${ }^{*}$ Cesare Gregoretti MD†

Purpose: To describe a minimally invasive alternative to conventional mechanical ventilation, using a small size uncuffed nasotracheal tube (translaryngeal open ventilation) paired with pressure control ventilation, in acute respiratory failure complicating chronic obstructive pulmonary disease (COPD).

Clinical features: Two cooperative COPD patients, who failed noninvasive mechanical ventilation, were intubated nasotracheally. Mechanical ventilation was initiated in pressure control mode via an uncuffed $6 \mathrm{~mm}$ tube.

Results: Respiratory rate improved after I hour (from 44 to 28 breaths $\cdot \mathrm{min}^{-1}$ in case I and from 32 to 25 breaths $\cdot \mathrm{min}^{-1}$ in case 2); $\mathrm{PaCO}_{2}$ decreased (from 120 to $62 \mathrm{mmHg}$ in case I and from 69 to $51 \mathrm{mmHg}$ in case 2); with pressure control mode levels of $45 \mathrm{~cm}$ $\mathrm{H}_{2} \mathrm{O}$ and $55 \mathrm{~cm} \mathrm{H}_{2} \mathrm{O}$ respectively. $\mathrm{PaO}_{2}$ increased from $40 \mathrm{mmHg}$ (with $\mathrm{FiO}_{2}$ 0.3) to $55 \mathrm{mmHg}$ (with $\mathrm{FlO}_{2} 0.3$ ) in the first patient and from $55 \mathrm{mmHg}$ (with $\mathrm{FIO}_{2}$ 0.4) to $60 \mathrm{mmHg}$ (with $\mathrm{FIO}_{2} 0.4$ ) in the second patient; $\mathrm{pH}$ improved from 7.18 to $7.3 \mathrm{I}$ in case I and from 7.22 to 7.39 in case 2. Patients were able to trigger the ventilator, speak, swallow and to clear secretions spontaneously. Both patients were ventilated for three days in this manner without any adverse effects. Both survived and were discharged home after 20 and 18 days in hospital respectively.

Conclusion: This very preliminary report suggests that, in carefully selected patients who fail mask ventilation, mechanical support with translaryngeal open ventilation can improve gas exchange, breathing pattern and tachypnea, without hindering glottic function.
Objectif: Décrire une variante, avec effraction minimale, de la ventilation mécanique traditionnelle qui utilise un petit tube nasotrachéal sans ballonnet (ventilation ouverte translaryngée) jumelé à la ventilation limitée par la pression, dans un cas d'insuffisance respiratoire aiguë compliquant une maladie pulmonaire obstructive chronique (MPOC).

Éléments cliniques : Deux patients souffrant de MPOC, chez qui la ventilation mécanique non effractive avait échoué, ont subi une intubation nasotrachéale. La ventilation mécanique a été amorcée en mode limité par la pression au moyen d'un tube de $6 \mathrm{~mm}$ sans ballonnet.

Résultats : La fréquence respiratoire s'est améliorée après une heure (de 44 à 28 respirations min $^{-1}$ dans le premier cas et de 32 à 25 respirations:min ${ }^{-1}$ dans le cas 2); la $\mathrm{PaCO}_{2}$ a diminué (de 120 à 62 $\mathrm{mmHg}$ dans le cas 1 et de 69 à $51 \mathrm{mmHg}$ dans le cas 2); en mode limité par la pression, les niveaux ont été de $45 \mathrm{~cm} \mathrm{H}_{2} \mathrm{O}$ et $55 \mathrm{~cm}$ $\mathrm{H}_{2} \mathrm{O}$ respectivement. $\mathrm{La} \mathrm{PaO}_{2}$ a augmenté, passant de $40 \mathrm{mmHg}$ (avec $\mathrm{FIO}_{2}, 0$,3) à $55 \mathrm{mmHg}$ (avec $\mathrm{FIO}_{2}$ 0,3) chez le premier patient et de $55 \mathrm{mmHg}$ (avec $\mathrm{HO}_{2}$ 0,4) à $60 \mathrm{mmHg}\left(\right.$ avec $\mathrm{HO}_{2}, 0,4$ ) chez le second ; le pH s'est amélioré de 7,18 à 7,31 dans le premier cas et de 7,22 à 7,39 dans le second. Les patients pouvaient déclencher le ventilateur, parler, avaler et expectorer spontanément. La ventilation s'est poursuivie ainsi pendant trois jours sans effets secondaires pour les deux patients. Ces derniers ont survécu et ont quitté l'hôpital après 20 et 18 jours respectivement.

Conclusion : Ce compte rendu très préliminaire signale que, chez des patients attentivement sélectionnés ne pouvant recevoir une ventilation au masque, l'assistance mécanique avec la ventilation ouverte translaryngée peut améliorer l'échange gazeux, le mode de respiration et la tachypnée, sans gêner la fonction glottique.

Form the Critical Care Division, ${ }^{*}$ Maisonneuve Rosemont Hospital, Montréal, Québec Canada; and the Intensive Care Unit, $†$ CTO,CRF, ICORMA, Torino, Italy.

Address correspondence to: Dr. Yoanna Skrobik, Critical Care Division, Hôpital Maisonneuve-Rosemont, 5415, boul. de l'Assomption,

Montréal, Québec HIT 2M4, Canada. Phone: 514-252-3400; Fax: 514-252-3806; E-mail: skrobiky@total.net

Accepted for publication June 5, 2001.

Revision accepted September 10, 2001.

This article is accompanied by additional audiovisual material that can be consulted at www.cja-jca.org 
$\mathrm{V}$

ENTILATORY support in respiratory failure using facial or nasal masks offers many advantages. ${ }^{1}$ Clinical reports including multicentre, randomized controlled trials indicate that noninvasive ventilation can decrease ventilator days, length of the intensive care unit (ICU) stay and the incidence of ventilator associated pneumonia. ${ }^{1-3}$ The reasons for this remain to be fully elucidated. Proposed explanations include preservation of glottic function, the elimination of accumulated secretions above the endotracheal tube cuff, ${ }^{4}$ and improved patient comfort with a decrease in the amount of sedation required. Mechanical ventilation with endotracheal intubation remains, however, the standard of care in patients with severe acute respiratory insufficiency, particularly those who have failed ${ }^{4}$ or are considered ineligible for mask ventilation. Recent publications ${ }^{5,6}$ also suggest that mask ventilation may not be safe for all patients.

Transtracheal open ventilation has recently been described in COPD ${ }^{7-9}$ Patients with acute respiratory failure who failed mask ventilation were randomized to either conventional mechanical ventilation through a cuffed orotracheal tube, or transtracheal open ventilation, defined as ventilatory support through an uncuffed mini-tracheostomy tube. Mechanical ventilation was delivered using a pressure control mode. Patients with transtracheal open ventilation maintained glottic function and were able to swallow, eat, and speak. They required far less sedation and had a dramatically decreased incidence of ventilator associated pneumonia. ${ }^{8}$

Performing a mini-tracheotomy is invasive and requires specific expertise. We hypothesized that attempting mechanical ventilation through a small size naso-tracheal tube used with a deflated cuff ("translaryngeal open ventilation") in COPD patients could provide adequate ventilatory support and be of benefit in terms of comfort and preserved glottic function. We wish to describe our initial experience with this technique.

\section{Clinical features}

Case 1

The first patient, a 68 -yr-old male with severe COPD (FEVl of $0.4 \mathrm{~L}$ ) on home oxygen therapy was admitted to hospital with acute hypercapnic respiratory failure. He complained of symptoms of upper respiratory infection and worsening dyspnea. On admission his heart rate was 123 beats. $\mathrm{min}^{-1}$, his blood pressure was $140 / 80 \mathrm{mmHg}$ with a pulsus paradoxus of 25 $\mathrm{mmHg}$. He had a respiratory rate of 44 breaths $\mathrm{min}^{-1}$. He was afebrile. His physical examination showed hyperinflation and diffuse inspiratory and expiratory wheezing with a prolonged expiratory phase. Chest $x$ ray showed no infiltrates; electrocardiogram was unchanged from his baseline (right atrial hypertrophy and right axis deviation) except for sinus tachycardia.

His arterial blood gas analysis on admission (with nasal cannulae delivering $6 \mathrm{~L}$ of oxygen a minute) showed a $\mathrm{pH}$ of $7.23, \mathrm{PaCO}_{2}$ of $95 \mathrm{mmHg}, \mathrm{HCO}_{3}$ of $34, \mathrm{PaO}_{2} 48 \mathrm{mmHg}$. Face mask ventilation was attempted but was not tolerated by the patient despite reassurance. With mild sedation (propofol infusion at 0.8 $\mathrm{mg} \cdot \mathrm{kg}^{-1} \cdot \mathrm{hr}^{-1}$ ) his $\mathrm{PaCO}_{2}$ rose to $120 \mathrm{mmHg}, \mathrm{Pa}_{2}$ dropped to 40 and he became more acidemic ( $\mathrm{pH} 7.18$ ).

The patient was still able to communicate and expressed anxiety at being unable to speak with an endotracheal tube in place. He accepted a trial with a small uncuffed endotracheal tube with the understanding that the treatment was experimental, might not work and require subsequent conventional endotracheal intubation with a full sized cuffed tube.

A 6-mm ID (Mallinckrodt Co) orotracheal 280$\mathrm{mm}$ long tube was inserted into the patient's nose and advanced blindly into the trachea after topical anesthesia. The cuff was inflated briefly to measure intrinsic positive end expiratory pressure (PEEP) while initiating mechanical ventilation in assisted pressure control mode with a standard ICU ventilator (Servo 300, Siemens Elema, Uppsala, Sweden). Static intrinsic PEEP was obtained with the patient as relaxed as possible. PEEP was set at $80 \%$ of the intrinsic PEEP ( 8 $\left.\mathrm{cm} \mathrm{H}_{2} \mathrm{O}\right) \cdot{ }^{10}$ The cuff was then deflated and expiratory volume measured via the ventilator. The inspiratory pressure was set between 45 and $55 \mathrm{~cm}$ of $\mathrm{H}_{2} \mathrm{O}$ to ensure expiratory volumes in the $250-300 \mathrm{~mL}$ range. The respiratory rate was set at 20 breaths. $\mathrm{min}^{-1}$ and the inspiratory time set to maximize patient comfort at $0.8 \mathrm{sec}$. The patient was able to trigger the ventilator with spontaneous breaths when the flow trigger was set to the $0.5 \mathrm{~L} \cdot \mathrm{sec}^{-1} \mathrm{~cm} \mathrm{H}_{2} 0$ range, with no autocycling. Gas exchange improved after one hour, with $\mathrm{PaO}_{2}$ levels stabilizing between 55 and $68 \mathrm{mmHg}$ with $30 \% \mathrm{FIO}_{2}$, and $\mathrm{PaCO}_{2}$ decreasing to values ranging from 62 to $67 \mathrm{mmHg}$. $\mathrm{pH}$ rose from 7.18 to 7.31 . The patient was ventilated in this manner, with daily adjustments for his PEEP to match his auto-peep level, for $72 \mathrm{hr}$. He was able to speak in brief sentences and was able to swallow well enough to allow for oral feeding (see audiovisual supplement at www.cjajca.org). The attending physician adjusted his therapy, which included antibiotics, corticosteroids, and inhaled bronchodilators. The only sedation required was a small dose of benzodiazepine at night. He was evaluated daily for clinical evidence of sinusitis, which 
did not occur. $\mathrm{PaCO}_{2}$ slowly returned to his baseline level of $55 \mathrm{mmHg}$, and he was extubated on the third day. Over the next $48 \mathrm{hr}$ he required intermittent face mask ventilation, and was then discharged to the ward and home after 20 days in the hospital. He requested that he never be subjected to standard orotracheal intubation again, having found this mode of ventilation much more comfortable.

Case 2

A (70-yr-old) severe COPD patients (FEVI of $0.45 \mathrm{~L}$ ) on home oxygen therapy was admitted to hospital with acute hypercapnic respiratory failure and symptoms of recent viral illness. His vital signs showed a heart rate of 112 beats. $\mathrm{min}^{-1}$, arterial blood pressure of $160 / 90 \mathrm{mmHg}$, and a respiratory rate of 38 breaths. $\min ^{-1}$. He was afebrile. His blood gases on admission on $2 \mathrm{~L}$ of oxygen via nasal cannulae revealed a $\mathrm{pH}$ of $7.32 \mathrm{PaCO}_{2}$ of $60 \mathrm{mmHg}, \mathrm{HCO}_{3}$ of 31 and $\mathrm{paO}_{2} 48 \mathrm{mmHg}$. Face mask ventilation (PSV $20 \mathrm{~cm} \mathrm{H}_{2} 0$, PEEP $4 \mathrm{~cm} \mathrm{H}_{2} 0$ ) was initiated. Blood gases did not improve after one hour due to mask intolerance $\left(\mathrm{pH} 7.33 \quad \mathrm{PaCO}_{2} 59 \quad \mathrm{mmHg} \quad \mathrm{Pa}_{2} \quad 50\right.$ $\mathrm{mmHg}$ ), with $\mathrm{O}_{2}$ at $4 \mathrm{~L}$ delivered via nasal prongs. Nose mask ventilation also failed. His blood gases deteriorated further $\left(\mathrm{pH} 7.22, \mathrm{PaCO}_{2} 69 \mathrm{mmHg} \mathrm{Pa}_{2}\right.$ $55 \mathrm{mmHg}$ ) with $\mathrm{O}_{2}$ delivered at $40 \%$ via a face mask for two hours. The patient was still able to communicate and refused to be intubated. He accepted a trial with a small endotracheal tube with the understanding the treatment was experimental.

A 6-mm ID (Rusch, Germany), $380 \mathrm{~mm}$ long tube was inserted, after topical anesthesia, into the patient's right nostril and advanced blindly into the trachea. The cuff was left deflated. The extrinsic PEEP was set at $4 \mathrm{~cm} \mathrm{H} \mathrm{H}_{2} \mathrm{O}$ without self-triggering. The pressure trigger sensitivity was set at $0.5 \mathrm{~cm} \mathrm{H}_{2} 0$. The patient was ventilated with a Siemens 300 ventilator (Siemens Elema, Uppsala, Sweden) in the assisted pressure control mode at a rate of 15 breaths $\mathrm{min}^{-1}$. The inspiratory pressure was set at $55 \mathrm{~cm} \mathrm{H} \mathrm{H}_{2} \mathrm{O}$ with an inspiratory time of one second to ensure expiratory volumes measured by the ventilator in the $250-300 \mathrm{~mL}$ range. Blood gases showed a marked improvement $(\mathrm{pH}$ 7.39, $\mathrm{PaCO}_{2} 51 \mathrm{mmHg} \mathrm{PO}_{2} 60 \mathrm{mmHg}$ on $\mathrm{FIO}_{2} 0.4$ ) after one hour. Respiratory rate decreased from 32 to 25 breaths $\mathrm{min}^{-1}$.

Within $24 \mathrm{hr} \mathrm{PaCO}_{2}$ dropped to $45 \mathrm{mmHg}$ with a $\mathrm{pH}$ of $7.44 ; \mathrm{PaO}_{2}$ rose to 70 with the same $\mathrm{FIO}_{2}$. Glottic function was not impaired (clinically) allowing the patient to speak and swallow well enough to allow for oral feeding as in the patient described above. Therapeutic interventions included antibiotics, corti- costeroids and inhaled bronchodilators. The patient required only a small dose of haloperidol for sedation. He was evaluated daily for clinical evidence of sinusitis. He was extubated successfully after $80 \mathrm{hr}$. After extubation 24-hr nose mask ventilation was maintained for two days. Subsequently, only nocturnal nasal ventilation was required and he could be weaned from mechanical ventilation nine days after hospital admission.

\section{Discussion}

In these case reports translaryngeal open ventilation improved gas exchange in awake COPD patients with acute respiratory failure. The patients described were offered an experimental treatment in the context of lack of improvement with mask ventilation, imminent respiratory failure, and their refusal of conventional intubation. The patients' level of consciousness, preserved glottic function, and lack of vomiting or gastric distension suggested it was safe to initiate translaryngeal open ventilation.

Noninvasive ventilation is usually carried out in pressure pre-set modes. Assisted pressure control ventilation was chosen rather than pressure support ventilation ${ }^{10}$ to avoid patient-ventilator dys-synchrony, because of the patient's inability to reach the flow threshold value due to air leaks. ${ }^{1}$ Proximal airway pressure was high during inspiration. Previous studies have shown that distal airway pressure does not rise, because of high endotracheal tube resistance. ${ }^{12-16}$ During expiration high tube resistance may be of concern; here expiration occurred partly through the native airway, decreasing the resistance caused by the tube, ventilator expiratory valve and circuit. ${ }^{17}$ With translaryngeal open ventilation PEEP could be applied to decrease the work of breathing or improve triggering. ${ }^{18}$

The patients tolerated the technique well. The uncuffed 6-mm ID tube interfered little with speech. Glottic function also seemed preserved clinically. Patients could ingest food and liquid. We did not observe any evidence of aspiration. The patients were able to cough and clear secretions. Endoscopic or radiologic investigations were not performed to validate objectively our clinical observations. "Silent" aspiration, although unlikely given the patients' clinical behaviour and course, could not be excluded.

The objective of the present report was to present the feasibility of improving gas exchange with translaryngeal open ventilation in conscious patients with acute decompensation of chronic respiratory disease. The technique, described in only two COPD patients, might not be applicable to patients with other clinical presentations, such as acute lung injury. Our clinical observations with regard to the preservation of glottic 
function, patient comfort and ability to communicate suggest there may be advantages to this technique. The benefits may parallel those observed in mask ventilated patients.

Conclusion

In summary, we describe two cases of translaryngeal open ventilation with pressure control mode for the treatment of respiratory failure in patients with COPD. While very preliminary, our observations suggest that this approach is well tolerated by patients and may preserve glottic function. Further evaluation of this approach is required.

\section{References}

1 Meduri GU. Noninvasive positive-pressure ventilation in patients with acute respiratory failure. Clin Chest Med 1996; 17: 513-55.

2 Torres A, Aznar R, Gatell JM, et al. Incidence, risk, and prognosis factors of nosocomial pneumonia in mechanically ventilated patients. Am Rev Respir Dis 1990; 142: 523-8.

3 Nava S, Ambrosino N, Clini E, et al. Nonivansive mechanical ventilation in the weaning of patients with respiratory failure due to chronic obstructive pulmonary disease. A randomized, controlled trial. Ann Intern Med 1998; 128: 721-8.

4 Stauffer JL. Complications of endotracheal intubation and tracheotomy. Respir Care 1999; 44: 828-43.

5 Hill NS. Noninvasive ventilation routine therapy for community-acquired pneumonia? Not so fast! (Editorial). Intensive Care Med 2001; 27: 797-9.

6 Brochard $L$. What is really important to make noninvasive ventilation work. Crit Care Med 2000; 28: 2139-40.

7 Gregoretti C, Foti G, Beltrame F, et al. Pressure control ventilation and mintracheotomy in treating severe flail chest trauma. Intensive Care Med 1995; 21: 1054-6.

8 Gregoretti C, Navalesi P, Squadrone V, Gottfried SB. Transtracheal open ventilation to treat acute exacerbation in non-invasive ventilation (NIMV) failures. Am J Critical Care Med 1999; 159: 3 Al5 (abstract).

9 Gregoretti C, Confalonieri M, Gottfried S, Turello M, Biolini P, Navalesi P. Effect of a new cuffless translaringeal ventilatory support in restricitve patients with acute on chronic respiratory failure. Am J Respir Crit Care Med 2000; 161: A384 (abstract).

10 Boysen $P G, M c$ Gough E. Pressure-control and pressuresupport ventilation: flow patterns, inspiratory time, and gas distribution. Respir Care 1988; 33: 126-34.

11 Calderini E, Confalonieri M, Puccio PG, Francavilla N, Stella L, Gregoretti C. Patient-ventilator asynchrony during noninvasive ventilation: the role of expiratory trigger. Intensive Care Med 1999; 25: 662-7.
12 Bach JR, Alba AS. Tracheostomy ventilation. A study of efficacy with deflated cuffs and cuffless tubes. Chest 1990; 97: 679-83.

13 Nomori H, Ishibara T. Pressure-controlled ventilation via a mini-tracheostomy tube for patients with neuromuscular disease. Neurology 2000; 55: 698-702.

14 Watt JWH, Fraser MH. The effect of insufflation leaks upon ventilation. A quantified comparison of ventilators. Anaesthesia 1994; 49: 320-3.

15 Watt JWH, Fraser $M H$. The effect of insufflation leaks in long-term ventilation. Waking and sleeping transcutaneous gas tensions in ventilator-dependent patients with an uncuffed tracheostomy tube. Anaesthesia 1994; 49: 328-30.

16 van Lunteren E, Van de Graaff WB, Parker DM, et al. Nasal and laryngeal reflex responses to negative upper airway pressure. J Appl Physiol 1994; 56: 746-75.

17 Banner MJ, Downs JB, Kirby RR, Smith RA, Boysen $P G$, Lampotang $S$. Effects of expiratory flow resistance on inspiratory work of breathing. Chest 1988; 93 : 795-9.

18 Petrof BJ, Legare M, Goldberg P, Milic-Emili J, Gottfried SB. Continuous positive airway pressure reduces work of breathing and dyspnea during weaning from mechanical ventilation in severe chronic obstructive pulmonary disease. Am Rev Respir Dis 1990; 141: 281-9. 